\title{
ANATOMIA MACROSCÓPICA DO TELENCÉFALO DE LOBO-GUARÁ
}

Bruno Aires Simões ${ }^{1}$, Zenon Silva ${ }^{2}$, Roseâmely Angélica de Carvalho Barros ${ }^{3}$ Tarley Santos Oliveira ${ }^{4}$, Eduardo Paul Chacur ${ }^{5}$

1. Graduando do Curso de Psicologia, Universidade Federal de Goiás - Regional Catalão, Catalão-GO, Brasil. bruno.aires.89@gmail.com.br

2. Docente do Instituto de Biotecnologia, Núcleo de Ciências Biológicas, Universidade Federal de Goiás - Regional Catalão, Catalão - GO.

3. Docente do Instituto de Biotecnologia, Núcleo de Ciências Biológicas, Universidade Federal de Goiás - Regional Catalão, Catalão - GO.

4. Graduando do Curso de Enfermagem, Universidade Federal de Goiás Regional Catalão, Catalão-GO, Brasil

5. Docente do Instituto de Biotecnologia, Núcleo de Ciências Biológicas, Universidade Federal de Goiás - Regional Catalão, Catalão - GO.

Recebido em: 08/04/2017 - Aprovado em: 10/06/2017 - Publicado em: 20/06/2017 DOI: 10.18677/EnciBio_2017A105

\section{RESUMO}

Por meio da Anatomia Comparativa, é possível confrontar e relacionar a forma e função das estruturas anatômicas, ainda não descritas, com aquela já bem estabelecida em outras espécies. Assim sendo, o objetivo desta pesquisa é o estudo da organização anatômica macroscópica do Telencéfalo do Lobo- Guará, canídeo neotropical, componente da fauna do cerrado brasileiro. Neste estudo são dissecados e analisados dois espécimes adultos, machos, que foram coletados mortos às margens de rodovias do Sudeste goiano. (SISBIO 37072/2). Os dados obtidos são descritos e comparados com aqueles da literatura, já bem estabelecida, em Cão. Em relação ao tamanho do animal o Telencéfalo do LoboGuará é relativamente pequeno e exibe um polo caudal bastante arredondado e repleto de sulcos e giros bem definidos, além disso, apresentam um pólo rostral ligeiramente afilado, o que confere ao hemisfério uma forma de grão de bico (Cicer arietinum) achatado dorso-ventralmente. Essa característica sugere um maior desenvolvimento cortical da metade rostral do cérebro de Lobo-guará, em relação ao Cão. Além disso, é composto por duas partes ou Hemisférios Cerebrais, separados por uma profunda Fissura Longitudinal. A superfície de cada hemisfério é marcada por sulcos e giros, à semelhança do que está descrito no Cão, todavia, possivelmente em razão do menor desenvolvimento da córtex neste canídeo alguns sulcos e giros não foram encontrados. Desse modo, embora em menor número, estão presentes no Lobo-Guará, ocupando locais e posições similares: Sulco Rinal; Sulco Silviano; Sulco Ectosilviano; Sulco Suprasilviano; Giro Silviano, Giro Suprasilviano; Giro Ectosilviano; Área Piriforme, entre outros.

PALAVRAS-CHAVE: Anatomia, Lobo-Guará, Sistema neural, 


\title{
MACROSCOPIC ANATOMY OF THE TELENCEPHALON OF MANED WOLF
}

\begin{abstract}
Through Comparative Anatomy, it is possible to compare and relate the form and function of anatomical structures, not yet described, with those already well established in other species. Therefore, the aim of this research is the study of macroscopic anatomical organization of the Telencephalon of maned wolf, neotropical canid, wildlife component of the Brazilian cerrado. In this study two adult specimens, males, were dissected and analyzed, which were collected dead on the highways of the southeast of the state of Goiás. (SISBIO 37072/2). The data are described and compared with those of literature, already well established, of dog. In relation to the animal's size the Telencephalon of the maned wolf is relatively small and exhibits a caudal pole quite rounded and full of well-defined sulci and gyri, also, presents a rostral pole slightly tapered, which gives the hemisphere a form of chickpea (Cicer arietinum) flattened dorsoventrally. This characteristic suggests an increased cortical development of the rostral half-brain of the maned wolf, in relation to the dog. Furthermore, consists of two parts or Cerebral Hemispheres, separated by a deep Longitudinal Fissure. The surface of each hemisphere is marked by sulci and gyri, similar to what is described in the dog, however, possibly due to lower development of the cortex in this canid, some sulci and gyri were not found. Thus, although fewer in number, are present in the maned wolf, occupying sites and similar positions: Rhinal Sulcus; Sylvian Sulcus; Ectosylvian Sulcus; Suprasylvian Sulcus; Sylvian Gyri; Suprasylvian Gyri; Ectosylvian Gyri; Piriformis Area, among others.
\end{abstract}

KEYWORDS: Anatomy, Neural System, Maned wolf

\section{INTRODUÇÃO}

A Anatomia é o ramo da ciência envolvida com o conhecimento da estrutura e a forma dos "seres vivos". Neste sentido, diferentes enfoques podem ser considerados, quando é possível estabelecer uma linha de estudo e ou pesquisa. Através da Anatomia Comparativa, é possível confrontar e relacionar a forma e função das estruturas anatômicas, com aquela já estabelecida em outras espécies, sendo este o escopo desta pesquisa em Lobo-Guará.

O Lobo-Guará é o maior canídeo Sul Americano. É um animal solitário, de cor laranja-avermelhada, possui orelhas grandes com pontas pretas. Quando adultos, pesam aproximadamente 23kg, medem entre 1,2 a 1,3m de comprimento, chegando o rabo a medir $47 \mathrm{~cm}$. Possui pernas longas e finas, e um corpo esguio, desenvolve uma andadura ou marcha desajeitada característica deste canídeo. $\mathrm{Na}$ natureza são arredios e de hábitos crepusculares. É uma espécie com hábito alimentar generalista, sendo sua dieta constituída por pequenos roedores, aves e frutos, principalmente da Lobeira, fruta à qual está associado o seu nome (TAVARES \& SOUZA 2000).

Este canídeo distribui-se amplamente no cerrado brasileiro, que, conforme MARINHO FILHO, (1996); OLIVEIRA \& MARQUIS, (2002), é o segundo maior bioma brasileiro, ocupando uma área aproximada de dois milhões de $\mathrm{Km}^{2}$, possui formação geográfica muito diversificada incluindo 
campos limpos, campos de altitude, cerradão, cerrado campestre, floresta de galeria e cerrado rupestre. Este ambiente geográfico abriga uma alta diversidade de espécies próprias da região e espécies endêmicas em corroboração com a heterogeneidade fisionômica.

A fauna do cerrado é composta por 194 espécies de mamíferos pertencentes a 30 famílias e nove ordens, entre elas, a Carnívora (MARINHO FILHO et al., 2002). Os argumentos que justificam a importância do estudo comparativo do Sistema Neural dessa espécie estão calcados na escassez de estudos e risco de extinção em que a espécie se encontra. Ademais, o Sistema Neural, representa um dos mais importantes aspectos da evolução, elementos fundamentais quando o interesse é a preservação e proteção de uma espécie (MARINHO FILHO et al., 2002).

Tendo em vista os argumentos apresentados, o objetivo desta pesquisa foi dissecar e descrever a Anatomia Macroscópica do Telencéfalo do Lobo- guará, enumerando e caracterizando os sulcos e giros das faces: dorsolateral, ventral e medial dos hemisférios, e confrontar os resultados com a literatura pertinente em outros canídeos.

\section{MATERIAL E MÉTODOS}

Esta é uma pesquisa descritiva, onde o Telencéfalo foi dissecado, no primeiro semestre de 2016 e as estruturas componentes analisadas e descritas. Os resultados são confrontados com as descrições pertinentes em Cão Doméstico, visto ser uma literatura relativamente bem estabelecida em espécies de grupos semelhantes.

Os dados estatísticos não são relevantes uma vez que se trata de resultados descritivos em um número pequeno de espécimes, já que, são animais em risco de extinção ou em vias de entrarem neste risco que são recolhidos mortos. Os Espécimes propostos para análise, nesta pesquisa, pertencem à ordem Carnívora, família Canidae e espécie: Chrysocyon Brachyurus (lobo-guará). Os dados for am coletados a partir da dissecação de três espécimes, que foram coletados mortos, por atropelamento, às margens de rodovias de Goiás e Minas Gerais (Autorização SISBIO no 37072/2). No laboratório de Anatomia, foram fixados em solução aquosa de Formol a 10\%, via perfusão através da artéria femoral e conservado em igual solução.

A preparação das peças anatômicas foi feita por dissecação macroscópica da calota craniana e região posterior do pescoço até a exposição completa dos ossos. Com uma serra para gesso, foram realizados cortes dos ossos da calota craniana no plano sagital mediano e para-mediano a três centímetros da primeira, em cada antímero. A remoção cuidadosa dos ossos foi feita utilizando osteótomos, boticão, formão e martelo até a exposição total do telencéfalo envolto pelas meninges. Na coluna vertebral foram realizados cortes paramedianos e remoção do arco vertebral, juntamente com o processo espinhoso, até a exposição da medula espinhal cervical. A remoção do material de estudo foi feita por descolamento da duramáter e secção dos nervos ópticos e trato olfatório e outros pontos de fixação óssea da duramáter. Uma vez fora da carcaça, o material de estudo fo $\mathrm{i}$ cuidadosamente limpo, removendo as meninges com uma pinça de relojoeiro e sob lupa com aumento de 10X. Os sulcos e giros, objeto principal de análise foram preservados, descritos e fotografados com uma 
câmera Sony Cyber Shot de 7.2 megapixels.

A terminologia adotada para a descrição dos resultados foi International Committee on Veterinary Gross Anatomical Nomenclature (2012). Esta pesquisa foi desenvolvida com parecer favorável do CEUA/UFU no067/12 do projeto intitulado "Anatomia Descritiva e Comparativa dos Animais Silvestres".

\section{RESULTADOS}

O Telencéfalo do Lobo-Guará é relativamente pequeno, em relação ao tamanho do animal. Este é a parte mais desenvolvida e vista como um todo possui aspecto comprimido latero-lateralmente, produzindo uma forma aproximada de um "grão-de-bico", cuja parte mais larga é voltada caudalmente e a parte mais estreita, fortemente comprimida e afilada, rostralmente. É composto por duas partes ou Hemisférios Cerebrais, separados por uma profunda Fissura Longitudinal. A superfície de cada hemisfério é marcada por depressões denominadas Sulcos. Os sulcos delimitam áreas circunscritas denominadas Giros. Em cada hemisfério identificam-se: uma Face Dorsolateral; uma Face Inferior e outra Medial.

Sulcos da Face Dorsolateral - A Face Dorsolateral é a maior entre as três, a superfície é marcada por sulcos e giros, sendo alguns mais visíveis e outros um tanto mascarados. Embora alguns sulcos sejam mais profundos, mais largos, e relativamente constantes, não é possível identificar, claramente, áreas topográficas identificadas como Lobos, pois a maioria dos sulcos e giros se estende por todo ou quase todo o hemisfério, com regularidade mais ou menos constante.

$\mathrm{Na}$ parte ventral da Face Dorso-lateral, um profundo e longo sulco se estende por todo o hemisfério, é o Sulco Rinal. O sulco ou Fissura Rinal é um dos sulcos mais evidentes na face dorsolateral do hemisfério cerebral do LoboGuará. Este está localizado na parte ventro-lateral do hemisfério, entre o neocórtex acima que inclui a maioria dos sulcos e giros do telencéfalo e a área olfatória abaixo, que inclui o Trato Olfatório e a Area Piriforme. Na altura da junção do trato olfatório com a área piriforme, o sulco rinal divide-se em dois ramos, um ascendente que se dirige caudal e dorsalmente, recebe a denominação de Sulco Silviano e um ramo descendente que se dirige caudal e ventralmente entre a área piriforme e o neocórtex parietal, denominado Sulco Rinal Caudal.

A parte do Sulco Rinal, rostralmente à sua ramificação é denominada Sulco Rinal Rostral, este por sua vez separa o trato olfatório dos giros dorsais. Na altura da parte media do Sulco Rinal Rostral surge um sulco bem marcado, que se dirige rostral e dorsalmente, na direção da Fissura Longitudinal é o Sulco pré-Silviano, o qual, próximo à sua extremidade rostrodorsal se ramifica em um ramo rostral e outro caudal, ambos posicionados paralelamente à Fissura Longitudinal, na mesma altura e em sentidos opostos (rostro-caudal) constituindo um sulco único Sulco Proreus. Contornando, a pouca distância, a extremidade do Sulco Silviano, há um sulco em forma de U invertido, denominado sulco Ectosilviano. Um pouco acima do Sulco Ectosilviano, exibindo a mesma forma deste, porém mais amplo, está um sulco bem marcado, o Sulco Supra-Silviano. Entre estes dois sulcos, caudalmente há um pequeno sulco posicionado verticalmente o qual é chamado de Sulco Entoectosilviano. Os Sulcos Ectosilviano e Suprasilviano podem ser ENCICLOPÉDIA BIOSFERA, Centro Científico Conhecer - Goiânia, v.14 n.25; p. 12532017 
subdivididos em duas partes: Rostral, e Caudal. Caudal e dorsalmente ao sulco Supra-Silviano Caudal há um sulco que acompanha a curvatura deste, é o Sulco Ectolateral. Acima do Sulco Supra-Silviano, a meia distância entre este e a Fissura Longitudinal está presente um sulco que se estende por quase toda a extensão do hemisfério, é o Sulco Lateral. Pequenos sulcos projetam-se dorsalmente a partir do sulco lateral, simplesmente como ramos deste.

Giros da Face Dorsolateral - A superfície do telencéfalo do LoboGuará apresenta áreas circunscritas entre sulcos, denominadas Giros ou Circunvoluções. Na face dorsolateral, há vários giros ou circunvoluções, alguns dos quais se estendem por todo o comprimento do hemisfério, enquanto outros são circunscritos a parte dele. Próximo à extremidade rostral, à frente do sulco Pré-Silviano está presente um grande giro denominado Giro Proreus. Na parte média e caudal do hemisfério, vários giros se dispõem de forma relativamente organizada no sentido rostro-caudal acompanhando a superfície convexa do hemisfério.

Assim, contornando a Fissura Silviana, entre esta e o Sulco Ectosilviano há um pequeno giro em forma de $U$ invertido, denominado Giro Silviano, o qual pode ser dividido em duas partes. A parte rostral é o Giro Silviano Rostral enquanto a parte caudal é denominada Giro Silviano Caudal. Contornando o Sulco Ectosilviano, entre este e o Sulco SupraSilviano circunscreve-se um giro contínuo, em forma de $U$ invertido é o Giro Ectosilviano que por sua vez pode ser dividido em Rostral e Caudal.

Acima do Sulco Supra-Silviano, estendendo-se por quase toda a extensão do hemisfério, há um longo giro denominado Giro SupraSilviano, o qual, posteriormente, está subdividido pelo Sulco Ectolateral em dois ramos denominados Giro Ectolateral Rostral e Giro Ectolateral Caudal. A parte rostral não dividida, deste giro denomina-se Giro Coronal. Ocupando quase toda extensão do hemisfério, limitado pela Fissura Longitudinal acima, e pelo Sulco Lateral abaixo, encontra-se o Giro Lateral. Este ocupa uma extensa área ao longo da Fissura Longitudinal, entre esta e o Sulco Lateral.

$\mathrm{Na}$ altura da junção do terço rostral com o terço médio o Giro Lateral é cortado transversalmente pelo Sulco Cruzado, que representa a continuação do sulco do cíngulo que avança sobre a superfície dorsolateral do hemisfério. A parte rostral do Giro Lateral, que contorna a extremidade do Sulco Cruzado é denominada Giro Sigmóide, a parte média é o Giro Lateral e a parte caudal, o Giro Pós-lateral. A parte do Giro Sigmóide, à frente do Sulco Cruzado é denominada Giro Sigmóide Rostral e a posterior Giro Sigmóide Caudal. No giro Sigmóide Caudal pode-se encontrar um Sulco PósCruzado.

Sulcos e Giros da Face Ventral - A face ventral do hemisfério cerebral do Lobo-Guará é relativamente irregular, mas não apresenta nenhum sulco ou giro bem marcado como aqueles da face dorsolateral. $\mathrm{A}$ estrutura telencefálica mais desenvolvida na face ventral é a Área Piriforme, esta é uma grande área cortical em forma de pêra, com a parte estreita voltada caudalmente, em continuação com o Giro Parahipocampal. A parte mais larga da Área Piriforme é orientada rostralmente. Esta recebe o Trato Olfatório. A Área Piriforme apresenta características de um giro do Telencéfalo, que está separado dos giros caudais da face dorsolateral pelo 
Sulco Rinal Caudal. Outras estruturas visíveis na face ventral, tais como o quiasma óptico, Túber cinéreo, corpo mamilar e pedúnculos cerebrais não pertencem ao telencéfalo, mas sim, a outros segmentos do encéfalo.

A área cortical localizada caudolateralmente aos pedúnculos cerebrais e que se acha em contato com a face cranial do cerebelo exibe com mais clareza, a extremidade caudal do Sulco Rinal Caudal, a extremidade caudal do Sulco do Cíngulo e o Sulco Parahipocampal. O Giro do Cíngulo avança sobre essa área, entre os sulcos Rinal Caudal e do Cíngulo, como Giro Parahipocampal, até encontrar e unir-se com a extremidade caudal da área Piriforme. A extremidade caudal do giro Marginal avança sobre essa face até encontrar o Giro Suprasilviano Posterior.

Sulcos e Giros da Face Medial - A face medial do Telencéfalo do Lobo-guará é relativamente lisa, sendo os sulcos e giros pouco pronunciados. Uma das estruturas mais facilmente notáveis é o Corpo Caloso, sendo, possível identificar as suas três partes: Joelho, Tronco e Esplênio. O Fórnix e o Septo Pelúcido são bem desenvolvidos. Aparentemente não há separação entre os dois talamos direito e esquerdo, ou seja, a Aderência Inter-talâmica ocupa a maior parte da face medial dos mesmos.

Disposto ao longo de toda a extensão da superfície dorsal do corpo caloso há um profundo sulco, o Sulco do Corpo caloso Próximo à borda dorsal do hemisfério, são encontrados dois sulcos bem demarcados e concêntricos, são estes, respectivamente, o Sulco do Cíngulo e o Sulco Supraesplenial. $\mathrm{Na}$ altura da junção entre o Tronco do Corpo Caloso com - Joelho do Corpo Caloso, dorsalmente, identifica-se o Sulco Cruzado, continuação dorsal do sulco do cíngulo. Este por sua vez corta a face medial do hemisfério, no sentido dorso- ventral, comunicando-se com o Sulco do Cíngulo. Paralelamente àquele, no sentido caudal, pode-se encontrar um segundo o Sulco Cruzado ou Sulco Cruzado Menor, que se inicia na superfície dorsal do hemisfério e corta a face medial do mesmo, até encontrar o Sulco do Cíngulo. Próximo à extremidade rostral do hemisfério são identificados vários sulcos pequenos que não estão claramente demarcados, entre estes o Sulco Genual e Ectogenual.

Os principais giros observados nesta face são: o Giro do Cíngulo, o Giro Esplenial e Giro Supraesplenial. Estes estão dispostos concentricamente em relação ao Esplênio do Corpo Caloso no sentido dorsocaudal. Rostralmente ao Joelho do Corpo Caloso a superfície medial do Telencéfalo é lisa, se comparada à superfície dorsolateral, apresentando apenas pequenos sulcos superficiais e giros mal definidos. 


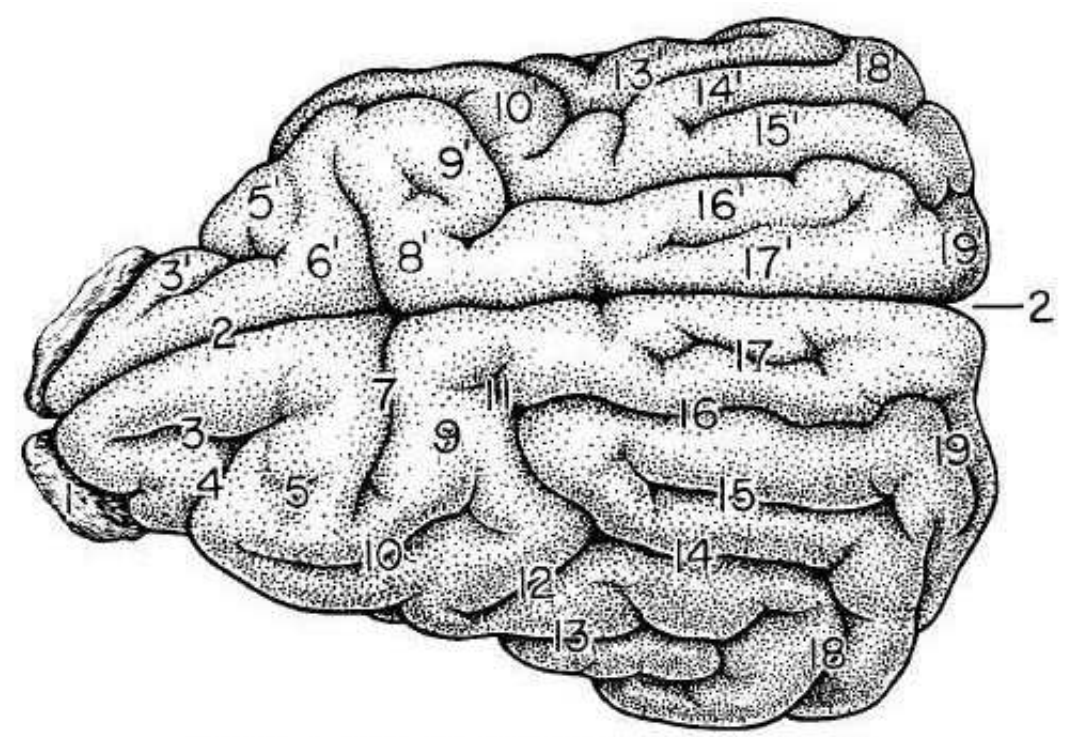

FIGURA 1 - Vista dorsolateral do cérebro de Cão (MILLER et al 1964): 1- Bulbo olfatório; 2-Fissura longitudinal; 3- Sulco Proreus; 4- Sulco pré silviano 4- Sulco pré cruzado; 6- Giro sigmóide cranial; 7- Sulco cruzado; 8- Giro sigmóide caudal; 9- Sulco pós cruzado; 9'- Giro pós cruzado; 10- Sulco coronal; 10'- Giro coronal; 11- Sulco pós cruzado, 12Sulco suprasilviano rostral; 13- Sulco ectosilviano; 13'- Giro ectosilviano; 14- Sulco suprasilviano médio; 14'- Giro suprasilviano médio; 15- Sulco ectolateral; 15'-Giro ectolateral; 16- Sulco lateral; 16'- Giro lateral; 17- Sulco entolateral; 17'- Giro entolateral; 18- Sulco suprasilviano caudal; 18'- Giro suprasilviano caudal; 19- Sulco lateral caudal; 19'Giro lateral caudal.



FIGURA 2 - Vista dorsolateral do cérebro de lobo-guará a- bulbo olfatório, b- giro Proreus, c- sulco Proreus, d- Sulco Cruzado, e- Giro Sigmóide Rostral, f- sulco suprasilviano, g- Fissura Longitudinal, h- Giro Suprasilviano, i- Giro Ectosilviano cranial, j- Sulco Ectosilviano, k- sulco lateral, l- Giro lateral, m- giro ectosilviano caudal, n- cerebelo.

Fonte: Bruno Aires Simões e Zenon Silva. 


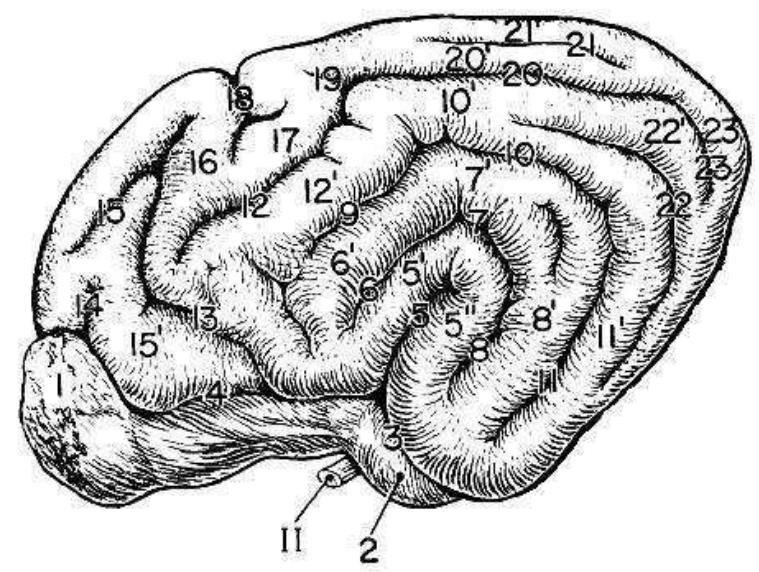

FIGURA 3- Visão lateral do cérebro do hemisfério esquerdo de Cão (MILLER et al 1964)1- Bulbo olfatório; 2- Área piriforme; 3- sulco rinal caudal; 4- Sulco rinal ventral; 5- Sulco silviano; 5'- Giro silviano ventral; 5" Giro silviano caudal; 6- Sulco ectosilviano ventral; 6'Giro ectosilviano ventral; 7- Sulco ectosilviano medial; 7'- Giro ectosilviano caudal; 8- Sulco ectosilviano caudal; 8'- Giro ectosilviano caudal; 9- Sulco suprasilviano ventral; 10- Sulco Suprasilviano medial; 10'- Giro suprasilviano medial; 11- Sulco Suprasilviano caudal; 11'Giro Suprasilviano caudal; 12- Sulco Coronal; 12'- Giro coronal; 13- Sulco pré-silviano; 14- Sulco olfatório; 15- Sulco proreus; 15'- Giro proreus; 16- Giro sigmóide ventral; 17Giro sigmóide caudal; 18- Sulco cruciato; 19- Sulco ansato; 20- Sulco lateral; 20'- Giro lateral; 21- Sulco entolateral; 21' Giro entolateral; 22- Sulco ectolateral; 22'- Giro ectolateral; 23- Sulco caudolateral; 23'- Giro caudolateral.

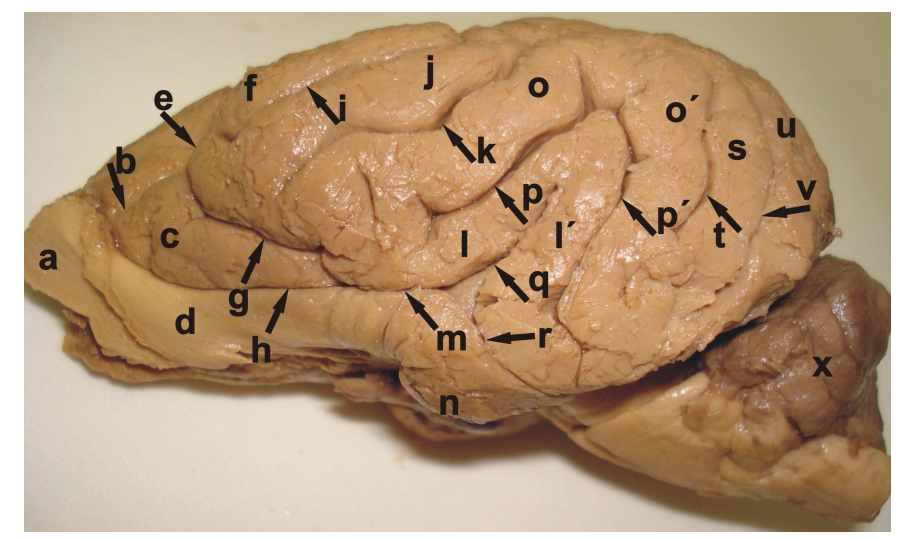

FIGURA 4- Visão lateral do cérebro do hemisfério esquerdo de lobo-guará: a- bulbo olfatório, b- sulco proreus, c- giro proreus, d- trato olfatório, e- sulco cruzado, f- giro sigmóide caudal, g- sulco pré-silviano, h- sulco rinal rostral, i- sulco lateral, j- giro suprasilviano, ksulco suprasilviano, l- giro Silviano rostral, l'- giro Silviano caudal, $\mathrm{m}$ - sulco rinal, $\mathrm{n}$ - área piriforme, o- giro ectosilviano cranial, o'- giro ectosilviano caudal, $p$ - sulco ectosilviano cranial, p'- sulco ectosilviano caudal, q- sulco Silviano, $r$ - sulco rinal caudal, s- giro ectolateral cranial, t- sulco ectolateral, u- giro ectolateral caudal, v- sulco lateral, x- cerebelo. Fonte: Bruno Aires Simões e Zenon Silva. 


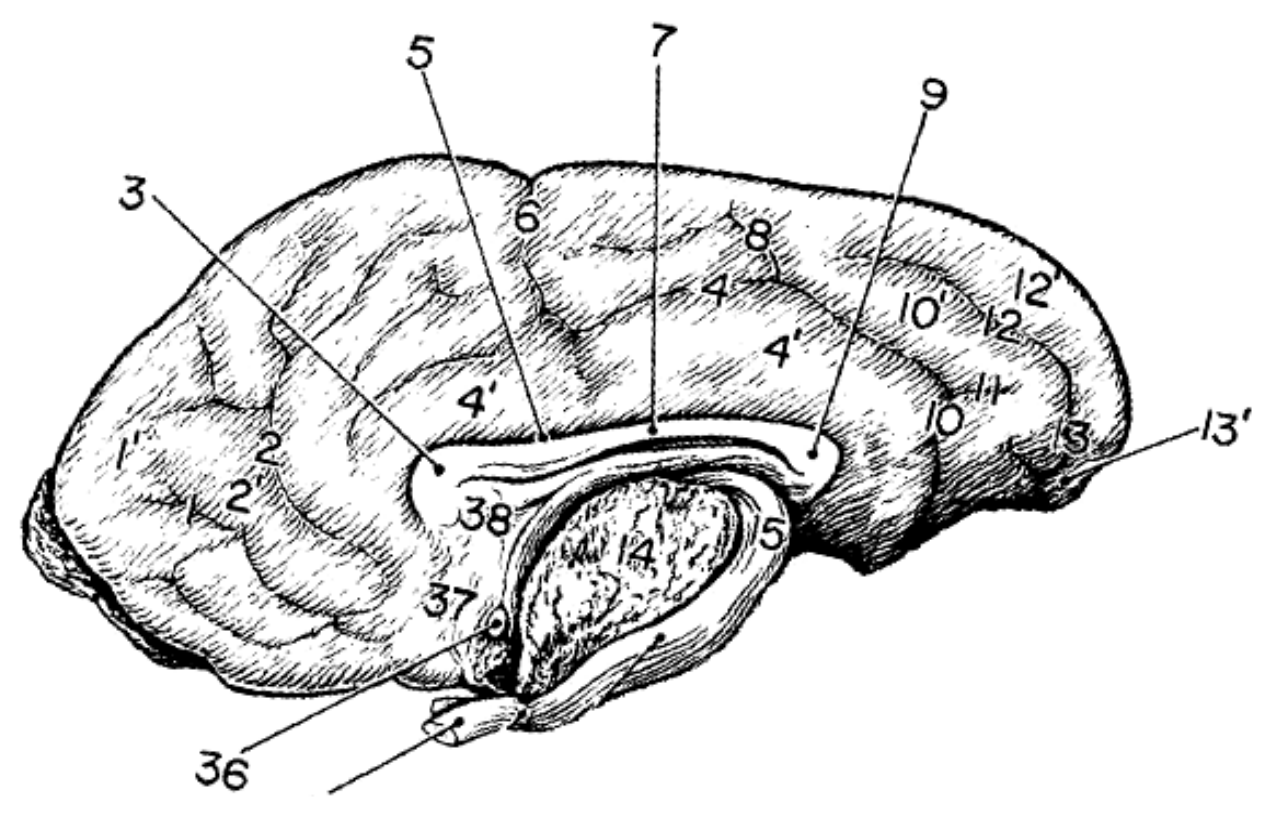

FIGURA 5 - Vista medial do hemisfério cerebral direito de Cão (MILLER ET AL 1964) 1- Sulco ectolateral; 1'- Giro ectolateral; 2- Sulco genual; 2'- Giro genual; 3- Joelho do corpo caloso; 4- Sulco do cíngulo; 4'- Giro do cíngulo; 5- Sulco do corpo caloso; 6- Sulco cruzado; 7- Tronco do corpo caloso; 8- Sulco cruzado menor; 9- Esplênio do corpo caloso; 10- Sulco Esplenial; 10'- Giro esplenial; 11- Ramo horizontal posterior do sulco esplenial; 12- Sulco supraesplenial; 12'- Giro supraesplenial; 13- Sulco pós-esplenial; 13'- Giro pós-esplenial; 37Giro paraterminal; 38- Septo pelúcido.



FIGURA 6 - Vista medial do hemisfério cerebral direito de lobo-guará: a- bulbo olfatório, b- giro proreus, c- sulco proreus, d- giro sigmóide cranial, e- sulco cruzado, f- joelho do Corpo Caloso, g- giro sigmóide caudal, h- sulco do corpo caloso, i- Sulco do corpo caloso, jcomissura anterior, $\mathrm{k}$ - sulco do cíngulo, $\mathrm{I}$ - sulco pós-cruzado, $\mathrm{m}$ - tálamo, $\mathrm{n}$ - giro parahipocampal, o- giro do cíngulo, $p$ - esplênio do corpo caloso, q- sulco supraesplenial, $r$ - giro esplenial, s- giro ectoesplenial.

Fonte: Bruno Aires Simões e Zenon Silva. 


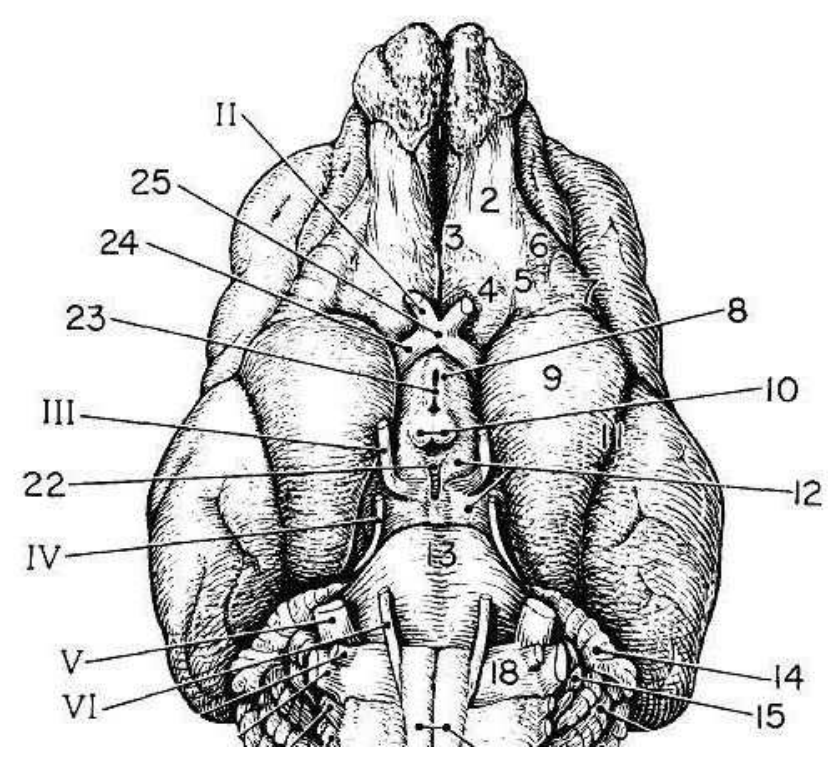

FIGURA 7 - Vista ventral do cérebro de Cão (MILLER et al 1964) - 1- Bulbo olfatório; 2Tracto olfatório; 3- Estria olfatória medial; 4- Substância perfurada rostral; 5- Estria olfatória lateral; 6- Giro olfatório lateral; 7- Sulco rinal rostral; 8- Túber cinéreo; 9- Área piriforme; 11 - Sulco rinal caudal.

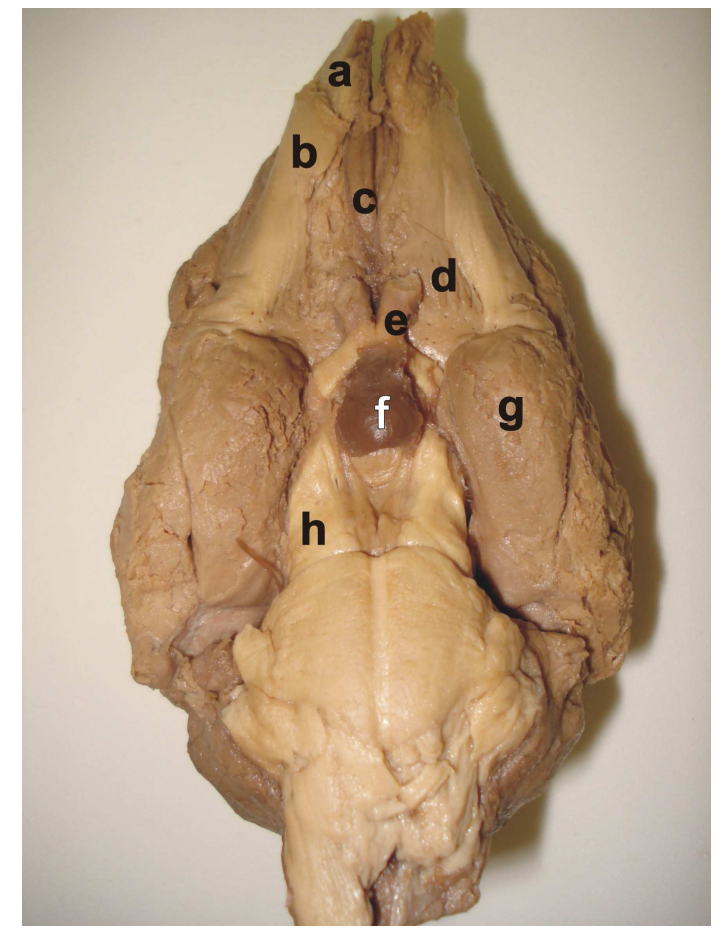

FIGURA 8 - Vista ventral do cérebro de lobo- guará: a- Bulbo olfatório, b- Trato olfatório, c- giro reto, d- Estria olfatória, e- Quiasma óptico, f- Hipófise, g- Área Piriforme, hPedúnculo Cerebral.

Fonte: Bruno Aires Simões e Zenon Silva.

\section{DISCUSSÃO}

Os resultados desta pesquisa são confrontados com as citações compiladas de MILLER et al., (1964), GETTY et al., (2008), dois clássicos da Anatomia animal. Não é feita nenhuma referência a outros animais por representarem grupos diferentes, assim sendo, as diferenças e ou 
semelhanças, por ventura presentes, não encontram bases sólidas para discussão.

Para MILLER et al., (1964) o Telencéfalo de Cão (Canis familiares) é formado por dois hemisférios separados na linha mediana pela Fissura Longitudinal. Neste sentido, as observações no Lobo-guará (Chrysocyon Brachyurus) revelam as mesmas características.

GETTY et al., (2008) citam que uma característica marcante dos hemisférios cerebrais de Cão é a extremidade ou polo rostral fortemente comprimida, configurando, em visão dorsal, um aspecto quase triangular com a parte mais delgada voltada rostralmente, e o polo caudal mostrando-se bastante arredondado. Os exemplares de Lobo-Guará, analisados nesta pesquisa apresentam hemisférios cerebrais com configurações similares às descritas em Cão, todavia, exibem um polo caudal bastante arredondado, repleto de sulcos e giros bem definidos, além disso, apresentam um polo rostral ligeiramente afilado, o que confere ao hemisfério uma forma de grão de bico (Cicer arietinum) levemente achatado dorso-ventralmente. Essa característica sugere que maior desenvolvimento cortical da metade rostral do cérebro de Lobo-guará, em relação ao Cão.

MILLER et al., (1964) citam que o Telencéfalo do cão está subdividido em regiões denominadas lobos: Frontal, Parietal, Occipital e Temporal, embora seus limites não sejam claros. No Lobo-Guará não há nenhuma evidência que delimite os lobos Telencefálicos, uma vez que não há sulcos ou depressões que sugiram tal definição. Os giros localizados caudalmente ao Sulco Silviano curvam-se rostralmente e continuam com a Área Piriforme, caracterizando uma área que se parece com o lobo Temporal de outros grupos, mas, nenhuma marca é vista que possa sugerir divisão entre os lobos Frontal, Parietal e Occipital. Assim sendo, nesta pesquisa foram tratadas como Regiões Frontal, Parietal e Temporal.

De acordo com MILLER et al., (1964) e GETTY et al., (2008), mais do que em outras espécies, os sulcos e giros do Telencéfalo de Cão estão dispostos concentricamente ao redor da Fissura Silviana, todavia, em Lobo-Guará verifica-se uma disposição dos sulcos e giros em torno da Fissura Longitudinal semelhante às descrições em cão, além disso, verifica-se que os sulcos e giros da córtex do Lobo-Guará são equivalentes aos descritos em Cão.

A configuração dos sulcos e giros do telencéfalo é semelhante para uma espécie, mas, variações ocorrem entre diferentes espécies e entre os hemisférios de um espécime (MILLER et al., 1964). Assim sendo, observa-se que, em Lobo-Guará, um pequeno sulco vertical situado entre os Sulcos Ectosilviano e Suprasilviano mostra-se maior do que aqueles descritos em Cão.

O Sulco Rinal é um dos mais evidentes e bem marcados sulcos do Telencéfalo do Cão MILLER et al., (1964); GETTY et al., (2008). Em Lobo-Guará as observações estão de acordo com as afirmações dos referidos autores, que, além disso, citam que o Sulco Rinal está localizado na face ventro-lateral do hemisfério cerebral, ao longo de toda a extensão, separando a parte, filogeneticamente, mais recente (neopalio ou neocórtex), localizada acima da córtex olfatória (Paleopalio ou paleocórtex) inferiormente. O sulco rinal do Lobo-Guará está igualmente, disposto. 
O Sulco Rinal de Cão exibe, na parte média, uma ramificação. O Ramo Dorsal é mais curto, dirige-se dorso-caudalmente e denomina-se Fissura ou Sulco Silviano. Já o Ramo Ventral é mais longo, flete fortemente no sentido caudo-ventral e recebe a denominação de Sulco Rinal Caudal, enquanto a parte do mesmo sulco, rostralmente à divisão passa a denominar-se Sulco Rinal Rostral MILLER et al. (1964) e GETTY et al., 2008). As observações feitas em Lobo-Guará sobre o Sulco Rinal, revelam uma configuração em acordo com as descrições compiladas em Cão.

MILLER et al. (1964); GETTY et al., (2008) citam que, em Cão, na altura da parte media do Sulco Rinal Rostral tem origem um profundo sulco, o Sulco Pré-Silviano que se orienta rostral e dorsalmente, na direção da Fissura Longitudinal. A extremidade rostral pode se unir a um inconstante sulco paralelo à fissura longitudinal denominado Sulco Proreus. As observações em Lobo-Guará são concordes com a referida citação, no atinente aos sulcos Pré-Silviano e Proreus,

Em Cão, segundo MILLER et al.,(1964), a Fissura ou sulco Silviano é idêntica àquela descrita por SISSON \& GROSSMAN (1953) quando afirmam que ela é relativamente curta e rodeada por três sulcos semicirculares concêntricos e os três sulcos que estão organizados em torno da fissura são, em ordem, os Sulcos Ectosilviano, o Suprasilviano e finalmente o Lateral ou Ectomarginal. MILLER et al., (1964) afirmam que em LoboGuará estão presentes os mesmos sulcos organizados de maneira semelhante.

O Sulco Ectolateral que segundo MILLER et al., (1964) dividem a parte caudal do Giro Suprasilviano em Suprasilviano Caudal e Giro Ectolateral está, igualmente, presente no Lobo-Guará. A parte média do Giro Lateral de Cão apresenta um pequeno sulco paralelo à fissura longitudinal denominado Sulco Entolateral. Este divide o Giro Lateral em giros Ectolateral e Lateral ( MILLER et al., 1964; GETTY et al., 2008).

Este sulco não é verificado em Lobo-Guará, possivelmente em razão do menor desenvolvimento da córtex neste canídeo.

$\mathrm{Na}$ face medial do hemisfério cerebral, MILLER et al. (1964); GETTY et al., (2008) descrevem o Corpo Caloso como a maior comissura branca entre os hemisférios, o qual forma o teto dos ventrículos laterais. As observações no Lobo-Guará revelam igualmente, a presença de um Corpo Caloso, porém, maior, mais espesso e mais bem delimitado do que aquele de Cão.

Em Lobo-Guará, as estruturas não corticais da face medial: Fórnix, Septo Pelúcido e Comissura Rostral são mais desenvolvidas do que aquela descrita em Cão, por MILLER et al., (1964), sugerindo que, em LoboGuará as conexões entre às áreas olfatórias do cérebro seriam mais intensas, talvez por ser um animal silvestre necessite de um faro mais aguçado para encontrar comida. Em contrapartida, os Sulcos Genual e Ectogenual dessa espécie, assim como seus respectivos giros, são mal definidos quando comparados com as descrições de MILLER et al., (1964) em Cão.

Como descrito em Cão, por MILLER et al (1964); GETTY et al., (2008), em Lobo-guará, o Giro do Cíngulo avança caudalmente sobre a face ventro-medial como Giro Parahipocampal. As dimensões do giro parahipocampal do Lobo-Guará são proporcionalmente, maiores do que 
aquelas descritas por MILLER et al., (1964); GETTY et al., (2008), em Cão, talvez porque a memória de curto prazo, assim como o comportamento emocional (afetivo) do animal silvestre exijam menos.

O Giro Parahipocampal do Lobo-Guará é delimitado dorsalmente pela parte caudal do sulco do cíngulo e ventralmente pelo sulco parahipocampal. Este continua rostralmente com a área piriforme e caudalmente com o giro do cíngulo, assim como descrevem MILLER et al., (1964); GETTY et al., (2008), em Cão. Sulcos e giros da face dorsolateral avançam sobre a face caudo-ventral do hemisfério cerebral, como no Cão, mas a nomenclatura não sofre alterações nesta área.

\section{REFERÊNCIAS}

GETTY, R. Sisson \& Grossman: anatomia dos animais domésticos volume 1. $5^{\text {a }}$ ed. Rio de Janeiro: Guanabara Koogan, 2008.

INTERNATIONAL COMMITTEE ON VETERINARY GROSS ANATOMICAL NOMECLATURE. Nomina anatomica veterinaria. 5. ed 2012.

MARINHO-FILHO, J.; RODRIGUES, F. H. G.; JUAREZ, K. M. The Cerrado mammals: diversity, ecology and natural history. In: The Cerrados of Brazil: Ecology and Natural History of a Neotropical Savanna. OLIVEIRA, P. S.; MARQUIS, R. J. New York: Columbia University Press, 2002.

MILLER, CHRISTENSEN E EVANS. Anatomy of the Dog. New York: W.B. Saunders Company. 1964.

OLIVEIRA, P. S.; MARQUIS, R. J. The Cerrados of Brazil: Ecology and Natural History of a Neotropical Savanna. New York: Columbia University Press, 2002.

TAVARES E SOUZA, L.R. Chrysocyon brachyurus - Ecologia e Comportamento do Lobo-guará. Brasília, 2000. 